\title{
Natural Meadows: Development of Ecotourism in Chaiyaphum Province
}

\author{
Tiwaporn Jaroenpon ${ }^{1}$, Boonsom Yodmalee ${ }^{1} \&$ Kosit Phaengsoi $^{1}$ \\ ${ }^{1}$ The Faculty of Cultural Science, Mahasarakham University, Khamriang Sub-District, Kantarawichai District, \\ MahaSarakham, Thailand \\ Correspondence: Tiwaporn Jaroenpon, The Faculty of Cultural Science, Mahasarakham University, Khamriang \\ Sub-District, Kantarawichai District, MahaSarakham Province 44150, Thailand. E-mail: \\ tjaroenpon146@hotmail.com
}

Received: April 24, 2014 Accepted: May 20, 2014 Online Published: June 4, 2014

doi:10.5539/ach.v6n2p82 URL: http://dx.doi.org/10.5539/ach.v6n2p82

\begin{abstract}
This is a qualitative investigation to assess the current state and development of ecotourism at natural meadows in Chaiyaphum Province, North-eastern Thailand. Research was conducted from October 2012 to October 2013. Data was collected from document study and field research. Tools used for data collection were basic survey, observation, interview and focus group discussion. Results show that there are three categories of meadows in Chaiyaphum: Siam tulip meadows, gustavia meadows and kamang meadows. The level of ecotourism at natural meadows in Chaiyaphum province is good. There are provisions made for tourists in each of the eight categories investigated: food, location, accommodation, safety, transportation, souvenirs, surrounding environment and customs, beliefs and ceremonies.
\end{abstract}

Keywords: ecotourism, meadows, Chaiyaphum, development, management

\section{Introduction}

Tourism is an integral part of modern human life. While once nature was viewed as a place of nourishment and support, it is now seen as a place for relaxation and recreation. This shift in mentality has allowed for the growth of the tourist industry, which has generated substantial income for society and enabled nations to progress and develop (Potong, 2007). Thailand is blessed with a fantastically diverse collection of natural resources that have seen the country rank as one of the most popular international tourist destinations. Tourism trends have shifted towards a more environmentally friendly and sustainable form of travel, as reflected by the strategy of the eleventh national development plan (Office of the National Economic and Social Development Board, 2009). The plan emphasized the importance of natural and cultural conservation and incorporation into a sustainable tourism model.

The meadows of Chaiyaphum are vital local resources that provide sustenance to both nature and the economy. Meadows are natural resources of no less importance than forests. In the past, meadows were a vital source of nutrition for humans, in the form of both vegetation and meat. In the current civilized world, these once fertile breeding grounds are in danger of being destroyed by encroaching urban landscapes (Tiyennoi, 1999). However, it is these diverse natural habitats that continue to support the wildlife that humans continue to harm (Tinarat, 2011). It is important that the model outlined by the Office of the National Economic and Social Development Board is followed to maximize the potential of the tourist attractions and to maintain the ecosystem in the area. The research team was thus interested in assessing the current state and development of ecotourism at natural meadows in Chaiyaphum Province, North-eastern Thailand. This study is important in its contribution to an under-represented geographical area in English ecotourism literature.

\section{Methodology}

This is a qualitative investigation to assess the development of ecotourism at natural meadows in Chaiyaphum Province, North-eastern Thailand in order to paint a clear picture of its current state. Research was conducted from October 2012 to October 2013. The research area was purposively selected using five criteria: 1) it was a tourist attraction in Chaiyaphum Province; 2) it was a tourist attraction with a prominent natural identity; 3 ) it was a tourist attraction with basic infrastructure; 4) there were health and safety provisions and service standards 
employed; 5) there were tourist conveniences on-site. From these five criteria, three locations were chosen: the Siam tulip meadows around the Pang Heuy mountain range, the gustavia meadows in the Sai Thong Waterfall Park and the Kamang meadows in Phu Khiao District. From the research area, ninety respondents were purposively selected to comprise the sample population for the investigation.

Data was collected from document study and field research. Tools used for data collection were basic survey, observation, interview and focus group discussion. The basic survey was used to gather general information about the respondents and the locations. The research team then conducted participant and non-participant observation at the three sites. Respondent were structurally interviewed to gather information related to the current state and development of ecotourism at the natural meadows, with unstructured interviews used to gather any additional information. The results were concluded in focus group discussions at each site with 8-10 individuals.

All data was validated using a methodological triangulation technique to examine whether data collected at different times, different places and from different people differed. The results were categorized according to the aims of the research and data was analyzed by analytic induction. Typological analysis was also conducted by separating the data into six groups: acts, activities, meaning, relationship, participation and setting. The results of the investigation are here presented as a descriptive analysis.

\section{Results}

\subsection{The Natural Meadows of Chaiyaphum}

Chaiyaphum is on the border of Isan, Thailand's north-eastern region and joins both Central and Northern Thailand. The majority of land in Chaiyaphum is mountain, forest and meadow. The province is famous for its colorful hillside meadows, which are populated by beautiful pink and purple Siam tulips. These wide, attractive meadows are found nowhere else in the world and are complimented by the local waterfalls, streams and pools that attract wildlife tothe area. There are three categories of meadows in Chaiyaphum: Siam tulip meadows, gustavia meadows and kamangmeadows. The Siam tulip meadows are found around the Pang Heuymountain range, such as the Pa HinNgamNational Park in Pong Nok, Yang Klak, Ban Rai and Watapaek Sub-districts, ThepSatit District, Chaiyaphum Province. These meadows are surrounded by forest (Figure 1).

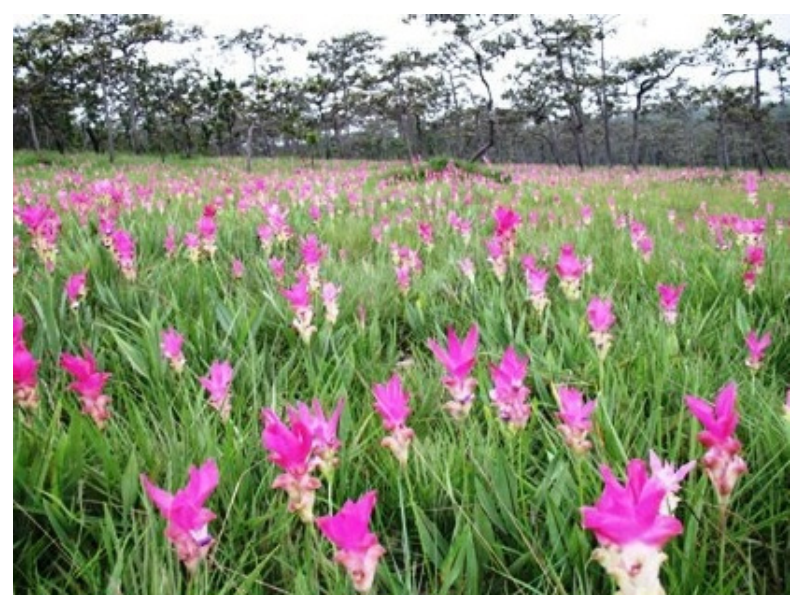

Figure 1. Siam tulip meadows in Chaiyaphum Province

The gustavia meadows are in the Sai Thong Waterfall Park, NongBuaRahaew District, Chaiyaphum. They cover approximately $319 \mathrm{~km}^{2}$ and are 300 to 1008 meters above sea-level. They are located in the Prayafaw and Pang Heuy mountain ranges and protected by conservation law. There are a total of five large Siam tulip and gustavia meadows. In these meadows, pink and white flowers will bloom during the rainy season, from about June to August. The forests throughout the meadows are mixed vegetation forests. Aside from the five large meadows there are smaller areas covered by various plants that bloom in purple, pink and orange from November to January, such as bladderworts, osbeckias and plains blackfoot. The flowers, combined with the winter fog, create an ambience that attracts tourists to the province. There is a three kilometer walking route through the meadows, with four designated viewpoints, the most famous of which is Pha Hum Hod (Figure 2). 


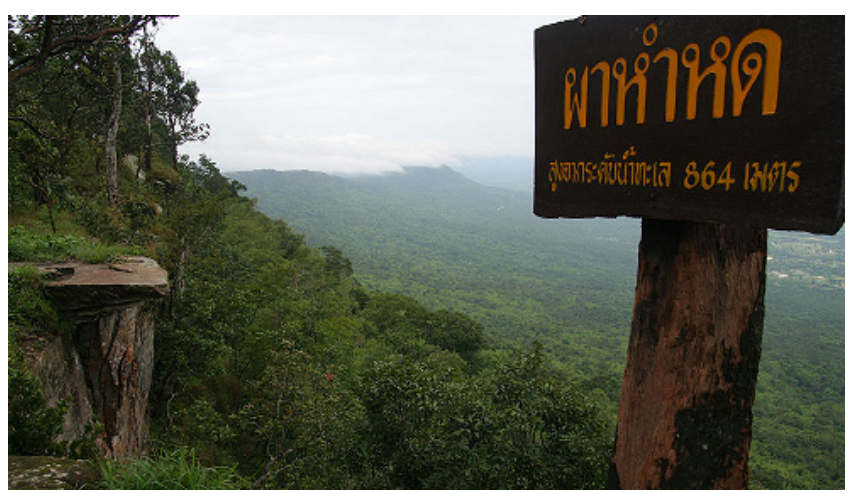

Figure 2. Pha Hum Hod viewpoint in Chaiyaphum Province

Kamangmeadows are large areas covering approximately 830 rai in the forest animal conservation area of PhuKhiao District. The meadows are a haven for local wildlife, including muntjac, chevrotain, Indian hog deer, Siamese fireback pheasant and peafowl. There are also mineral licks for animals to find precious nutrients. The grassland is periodically burned to allow grass buds to emerge and provide food for the animals and other vegetation is planted, such as banyan trees and jambolan plum. The kamangmeadows are open from $8 \mathrm{am}$ to $3 \mathrm{pm}$ every day but are closed to tours during the three month fertile period from the middle of August to the middle of October.

\subsection{The Current State of Ecotourism at Meadows in Chaiyaphum}

The research team investigated eight areas of ecotourism at the Chaiyaphum meadows. These were food, location, accommodation, safety, transportation, souvenirs, surrounding environment and customs, beliefs and ceremonies.

There are shops selling food along routes into the meadows, including canteens, restaurants serving food from each of the four Thai regions, made-to-order restaurants, boiled rice soup stalls, self-service restaurants and local homemade eateries. Restaurants have been specifically developed to serve the tourists visiting the meadows, who can choose to eat on-site or take away. If tourists elect to take food into the meadows, they must obey the park rules regarding consumption of food and waste disposal. The meadow locations are well maintained for tourism. There are staffed car parks for visitors at each of the meadows. Adequate toilet facilities are provided at each site and they are regularly maintained. An area is also designated at each meadow as a camping site. Aside from camping, sufficient, comfortable and standardized accommodation is provided on-site in the form of individual rooms or group rooms. Each type of accommodation package comes with the option of food, meeting rooms, local guides and activities.

The tourist attractions have cooperated with Chaiyaphum Provincial Administration to control traffic and ensure road safety. Road safety meetings are held between representatives of the attractions, local police and local administration and personnel are trained in the use of communication tools to report accidents. The traffic regulations have been developed to minimize accidents. Traffic on the roads into the meadows is controlled, especially during the high season and peak days. Additional staff members are employed to specifically deal with traffic. There are first aid units on-site at the attractions, staffed by regular volunteers and nurses, with a permanently stationed ambulance in the event of an emergency. Transportation routes have been developed for the tourist attractions and it is possible to access the meadows by car from two directions or by train to BuaYai station and public transport to the meadows. The nearest airport is in KhonKaen Province. There are marked footpaths and cycle paths around the meadows.

There is a variety of souvenirs available for tourists to buy. Agricultural goods include processed mushrooms, mushroom naem, daikon, bamboo and Siam tulip saplings. Local handmade products include mudmee silk, cotton, khid fabric, basketry and coconut-shell lampshades. The surrounding environment of the meadows is forest, water sources, rocks and local wildlife. The meadows themselves are home to many species of flower, including Siam tulip and gustavia. These are all naturally occurring. There are NyahKur people living in Ban Rai Sub-district, ThepSatit District, whose occupation is foraging from the forest. Their principle form of income is selling the goods they find, especially local honey. During the Thai Songkran festival from $13^{\text {th }}$ to $15^{\text {th }}$ April, the NyahKur people hold their pahawkaopoy ceremony to make merit and to ask forgiveness from the bees. 


\subsection{Development of Ecotourism at the Meadows of Chaiyaphum}

Ecotourism at the meadows has been developed in terms of location, management, activities and participation. The meadows have been incorporated as part of protected national parks, namely Pa HinNgam National Park and Sai Thong National Park. Not only does this aid conservation, but it also increases the reputation of the meadows among visiting tourists. The meadows are divided into specific areas to help with maintenance and management. There are opening and closing times for the forest parks, which restrict human impact on the natural environment.

There is continuous management of natural resources and the surrounding environment at each of the meadows. Authorities aim to reduce human impact on nature and also the impact of tourism on traditional society by promoting responsible travel. The Siam tulip meadows have been divided into five areas: service zone, outdoor recreation zone, primitive zone, recovery zone and special use zone. The service zone is the built area for tourist conveniences, facilities and accommodation. The outdoor recreation zone is an area for tourist relaxation and education. There are basic built facilities and the key features are a nature trail, nature interpretation signs, bird-watching huts and horse rides. The primitive zone is an area of fertile nature and natural wildlife habitat. Activities in this area are restricted to authorized research and official tasks. The recovery zone is an area that has been affected by human activity and is in a state of intensive care. Reforestation and planting is organized in the recovery zone. The special use zone is for the organization of special activities.

\section{Discussion}

Chaiyaphum is spoilt for well-managed natural resources that attract tourists to the province. The ecotourism potential of the Chaiyaphum meadows must be continuously developed to appeal to visitors. There must be no negative effect on the environment as a result of tourism (Fennell, 1999). The situation of Chaiyaphum mirrors the state of ecotourism in Sri Nakharin Dam National Park in Kanchanaburi. Satitya Mingwong (2007) found an area of plentiful natural resources that required continual management to bring tourism into line with international standards.

Results into the current state of ecotourism at the meadows of Chaiyaphum led the research team to note the following points. Food services are areas of tourism that the local communities can and must participate in $(\mathrm{Gu}$ \& Jiang, 2002). Community participation has the dual effect of increasing local income and strengthening the identity of the attraction. This is especially the case for ecotourism and the type of visitor drawn to natural attractions (Ballantine \& Eagles, 1994). Parking areas and toilets are necessary for any tourist attraction but it is especially important to ensure these facilities are ready for the tourist high season and festivals. The extent to which they need to be developed must come from experience and evaluation within the attraction (Hvenegaard \& Dearden, 1988; Janpanit, 1996). Julian Steward (1955) states that culture is a tool allowing humans to adapt to their surrounding environment. By ensuring that the cultural requirements of tourists are met, the tourist attractions will enjoy an enhanced reputation. Accommodation is a factor that draws tourists to a place and cleanliness is a factor that ensures they stay. For this reason, attractions must emphasize a strict and thorough cleaning regime and employ sufficient staff to cover cleaning duties. This is a response to tourist needs, a prerequisite for the survival of tourist attractions and culture (Malinowski, 1993). One area in which tourist needs have been met is the provision of health and safety standards, specifically resident nurses during high season. As Chalong Kongdeum (2005) noted, without adequate health and safety provisions, the potential of tourist attractions is significantly reduced. The nature trails and walkways through the meadows conserve nature by restricting tourist walking paths and provide a facility for tourists (Richardson, 1993). Suitable and sufficient access routes are also a means of advertising for the tourist attractions (Meemoo, 2009).

\section{Conclusion}

The current state of ecotourism at natural meadows in Chaiyaphum province is at a good level. There are provisions made for tourists in each of the eight categories investigated: food, location, accommodation, safety, transportation, souvenirs, surrounding environment and customs, beliefs and ceremonies. Furthermore, the division of tourist sites into areas denoting the permissible level of human intrusion is a positive step for the conservation of this important and beautiful natural resource. Development must continue to protect the interests of nature, while adhering to the demands of tourists.

\section{References}

Ballantine, J. L., \& Eagles, P. F. J. (1994). Defining Canadian ecotourists. Journal of Sustainable Tourism, 2(4), 210-214.

Fennell, D. (1999). Ecotourism: An introduction. London: Routledge. 
Gu, L., \& Jiang, C. (2002). Analysis of the components and characters of ecotourism effect. Journal of Zhejiang Forestry College, 19(3), 292-295.

Hvenegaard, G. T., \& Dearden, P. (1988). Ecotourism versus tourism in Thai national parks. Annals of Tourism Research, 25(3), 700-720.

Janpanit, S. (1996). Indigenous knowledge in natural resource management: The case of two villages in Thailand. PhD Thesis. Madison: The University of Wisconsin, Madison.

Kongdeum, C. (2005). Potential of Salawan National Park, Mae Hong Son Province as an ecotourism attraction [in Thai]. PhD thesis, Chiang Mai University, Chiang Mai.

Malinowski, B. (1993). The early writings. In R. J. Thornton, \& P. Skalnik (Eds.), Cambridge: Cambridge University Press.

Meemoo, T. (2009). Potential and method of ecotourism management in Tahin-Ngom Sub-district, Mueang District, Chaiyaphum Province [in Thai]. PhD thesis, Mahasarakham University, Maha Sarakham.

Mingwong, S. (2007). The state of the Sri Nakharin Dam National Park ecotourism attraction in Kanchanaburi Province [in Thai]. PhD thesis, Sri Nakharinwirot University, Bangkok.

Office of the National Economic and Social Development Board. (2009). 1 $11^{\text {th }}$ National economic and social development plan (2012-2016) [in Thai]. Bangkok: Office of the National Economic and Social Development Board.

Potong, K. (2007). Perspectives of Thai tourists towards ecotourism management: A case study of Khao Yai National Park [in Thai]. PhD thesis, Naresuan University, Phitsanulok.

Richardson, J. (1993). Ecotourism \& nature based holidays. Sydney: Australian Print Group.

Steward, J. (1955). Theory of culture change: The methodology of multilinear evolution. Champaign, IL: University of Illinois Press.

Tinarat, K. (2011). The ecosystem. Retrieved from http://psc.pbru.ac.th/lesson/index-ecosystem.html

Tiyennoi, W. (1999). Management of natural resources [in Thai]. Bangkok: Aksorn Pattana

\section{Copyrights}

Copyright for this article is retained by the author(s), with first publication rights granted to the journal.

This is an open-access article distributed under the terms and conditions of the Creative Commons Attribution license (http://creativecommons.org/licenses/by/3.0/). 